\title{
Steps Towards an Evolutionary Account of Argumentative Competence
}

\author{
CRistián SANTibáÑez YÁÑÉZ
}

Centre for the Study of Argumentation and Reasoning (CEAR)

Faculty of Psychology

Diego Portales University

Grajales 1746

Santiago

CHILE

Cristian.santibanez@udp.cl

\begin{abstract}
In this paper a tentative explanation of the competence of argumentation from an evolutionary point of view is offered. Because in contemporary argumentation theory and the informal logic approach the evolutionary perspective has been neglected, this paper gives an initial overview on the matter with the hope that core aspects of the argumentative faculty-such as argumentative normativity, the function of arguments, or fallacious moves, among others - can be seen differently afterwards. In order to specify the proposal, the main concepts considered are the notion of collective intentionality, cooperation, reputation, niche construction and, of course, basic evolutionary terms.
\end{abstract}

\begin{abstract}
Dans cet article, nous suggérons une explication de la compétence argumentative d'un point de vue évolutionniste. Comme la théorie de l'argumentation contemporaine et la logique non formelle ont négligé la perspective évolutionniste, nous en donnerons un premier aperçu en espérant offrir une nouvelle perspective sur certains aspects essentiels de la faculté argumentative-notamment en ce qui concerne la normativité des argumentations, la fonction des arguments et les raisonnements fallacieux. En plus de concepts de base en théorie de l'évolution, les principaux concepts que nous utiliserons seront ceux d'intentionnalité collective, de coopération, de réputation et de développement de niche.
\end{abstract}

Keywords: adaptation, argumentation, cooperation, evolution, niche, reputation

\section{Introduction}

Recently, Michael Tomasello (2014, pp. 110-111) has proposed a novel account about why human agents give reasons. In his view, "With modern humans and their skills of conventional linguistic communication, we get to full-blooded reasoning, where 'reasoning' means not just to think about something but to explicate in conventional form-for others or oneself- the reasons why one is thinking what one is thinking." The key 
point is that arguing in this way assumes a cooperative context. As Darwall (2006: p. 14) puts it: "It is only in certain contexts, say, when you and I are trying to work out what to believe together, that either of us has any standing to demand that one another reason logically."

Certainly, Tomasello is not the first one trying to explain reasoning from an evolutionary point of view. Since the famous Wason's selection task, many renewed efforts have been made by other authors. These efforts combine different insights: psychology of reasoning, evolutionary psychology, cognitive sciences. Some of these will be sketched in section 2. Nonetheless, what the majority of those analyses have in common is that they offer descriptions of the kind of cognitive mechanisms that supposedly underlie human agents' reasoning and decision making, instead of viewing the practice of exchanging reasonsarguing — as a distinctive social behaviour.

In this paper, and following in this respect what mainstream argumentation theory has sharply distinguished (Toulmin, Rieke \& Janik, 1979; van Eemeren \& Grootendorst, 1992, 2004; Tindale 1999; Walton, 2013), argumentation is understood as an activity in which a point of view advanced by an agent is rejected, doubted, or challenged by another agent (or many others), and then some reasons are offered to support this point of view, reasons that are in turn again challenged, and so on until the disagreement is resolved. If we take Tomasello's account of giving reasons, this basic definition of argumentation is partially captured.

In my opinion, what is missing in the general existing literature of psychology of reasoning, cognitive approaches and decision making theory's accounts of reasoning, is a full collectivistic explanation of the activity of exchanging reasons and not only a psychological analysis of one-shot reason giving as a retrospective justification of a decision, belief or action; furthermore, this literature sees the activity of giving reasons as a mental ability serving individual fitness, which is a very unbalanced account of a behaviour in which at least two parties play decisive roles. In order to add more elements to this ongoing discussion, this paper proceeds as follows. In section 2, some important evolutionary perspectives on reasoning are discussed; these perspectives have been selected because they give interesting feedback on a social evolutionary account. In section 3, my view on the matter is detailed, using some core concepts of an explicit interdisciplinary research anchored in the evolutionary analysis of social behaviours. In the conclusion, the main points 
of my account are emphasized and some projections of the discussion are suggested.

\section{Social roots of argumentation: alternative evolutionary accounts}

Cosmides, one of the pioneers of what is known today as evolutionary psychology (see Laland \& Brown, 2002), claimed:

A cognitive system can generate adaptive behavior only if it can perform the specific information-processing tasks entailed by the need to satisfy these constraints. Consequently, for evolutionarily important problem domains, humans must have evolved "Darwinian algorithms"- specialized learning mechanisms that organize experience into adaptively meaningful schemas or frames. When activated by appropriate problem content, these innately specified "frame-builders" should focus attention, organize perception and memory, and call up specialized procedural knowledge that will lead to domain-appropriate inferences, judgments and choices. Like Chomsky's language acquisition device, these inferential procedures allow one to "go beyond the information given" (Bruner, 1973) to reason adaptively even in the face of incomplete or degraded information. (Cosmides, 1989, p. 195.)

For Cosmides, logic is not considered as the epitome of human reasoning anymore; second, logic, or rules of inference, is not a content-independent cognitive process; and third, it is plainly false that there is only one single cognitive processnamely the logical inferential process in any of its forms - that governs reasoning in all the specific domains in which it is used to resolve problems. There are, as the quote shows, at least three evolutionary arguments to support these claims: (1) the more important the adaptive problem, the more natural the selection would have been to produce special-purpose mental algorithms; (2) considering reasoning adaptively is more advantageous than considering it logically because "this allows one to draw conclusions that are likely to be true, but cannot be inferred by strict adherence to the propositional calculus" (Cosmides, 1989, p. 193); and (3) not even all the mechanisms of the cognitive architectural general domain could have produced fit behavior that demanded specific and changing adaptations under Pleistocene era conditions. As is well known, Cosmides's modular perspec- 
tive has amounted to the meta-representational view on reasoning (Sperber, 2001; Mercier \& Sperber, 2011).

From the point of view of the logic of social exchange, Cosmides's thesis is that reasoning evolved as a highly flexible competence to exchange goods, services, and privileges cooperatively increasing the fitness chances of individuals. For humans in the Pleistocene, living in small groups was conducive to processing information strategically for social exchange. In other words, the intensive social conditions increased the pressure to select a finer reasoning capacity. Cosmides and colleagues offer two reasons for the latter claim: (1) the human mind must have algorithms that produce and work on the cost-benefit representation of social exchanges, which each individual assumes will have net benefits, otherwise social exchange could not have evolved; and (2) the human mind must include inferential procedures that make individuals good at detecting cheaters of social contracts, otherwise the individual lacking this capacity would pay more costs in continuous exchanges and would therefore be selected against.

The argumentative faculty viewed from this perspective could be considered part of a mechanism designed to resolve specific problems. Nonetheless, it is not clear how exactly the communicative dimension of the argumentative competence could fit in this picture, because the specialized cognitive module must be directed to specific content, which in turn potentially results in as many modules as specific performative tasks and contents. In principle, there would be many modules, as many specific activities can be recognized in the practice of arguing (which Hample (2005) labeled the argumentative frame), such as: arguing as play, showing intellectual capacities, resolving problems, deciding a course of action, cooperatively helping others, etc. At this point, Cosmides (1989) asserts that:

Specifically, an evolutionary perspective suggests that natural selection has shaped how humans reason by creating specialized, domain-specific cognitive mechanisms designed to solve discrete adaptive problems by activating reasoning procedures appropriate to the domain encountered. Evidence for the existence of such mechanisms is: (1) reasoning performance is altered depending on what content the subject is asked to reason about; and (2) such reasoning performance is altered by specific content in the predicted adaptive direction." (Pp. 190191.) 
However, Cosmides does not take into account the flexible capacity of cognitive agents of robustly tracking the environment using the strategy of decoupling representations - this is to say, the cognitive skill of decoupling true representations from specific actions in order to apply them to other purposes. In particular, Sterelny $(2003)^{1}$ has argued that it is evolutionarily inconsistent to maintain that highly cognitive skilled organisms have representations that react by means of cue-bounded behavior. On the contrary, these agents enrich their capacity of response to the difficulties of the environment by avoiding representation-forming mechanisms that are maximally accurate, because it would be inefficient and economically a disaster to have an internal tracking system to detect $X$ only when - the exact$\mathrm{X}$ is present. For defense purposes for example, it would be good to have, cognitively speaking, a system that reacts by taking into account information that conveys enough similarity to an original or exact cue of the vicinity of a tiger.

A more interesting hypothesis about the social pressure on the evolution of reasoning primates, our ancestors, is the need of deontic reasoning within hierarchical relationships among social agents. This hypothesis has been proposed by Cummins in several publications (1996a, 1996b, 1996c, 1998, 2003). She points out that hierarchical domination pressurizes primates' cognitive capacity to make transitive inferences and that, in turn, the need to solve practical issues puts pressure on deontic reasoning. She states:

The argument that Cheney and Seyfarth put forth regarding the capacity to make rank discriminations and transitive inferences is as follows: One strategy for working out dominance relations is simply to observe and remember the outcome of dyadic encounters between each pair of individuals in one's group until one can work out a sequential ordering of individuals indicating $\mathrm{A}$ is dominant to every-one, B to everyone but A, and so on. As group size increases, however, the number of outcomes that must be memorized grows exponentially. Another strategy is to reason transitively, that is, to infer some dominance relations based on knowledge of others: if one knows $\mathrm{A}$ is dominant to $\mathrm{B}$, and $\mathrm{B}$ to $\mathrm{C}$, then one can infer that $\mathrm{A}$ is also dominant to $\mathrm{C}$ without ever having observed a dyadic encounter between $\mathrm{A}$ and C. (...) The domain-specificity that is apparent in the transitive reasoning of non-human primates and which emerges early

\footnotetext{
${ }^{1}$ See Christensen (2010) for a critical assessment of the notion of decoupled representations.

(C) Cristián Santibáñez Yáñéz. Informal Logic, Vol.35, No. 2 (2015): pp. 167-182.
} 
in human development seems to be tied specifically to working out dominance relations. This is consistent with the proposal offered here that certain aspects of the human reasoning architecture were shaped by the need to solve problems relating to life within dominance hierarchies. (Cummins, 1996, pp. 469-470.)

However, one of the problems with this view is that it assumes that agents have a huge capacity to process and control all the complex memories regarding dyadic encounters, whereas the evidence of human cognitive capacity shows otherwise (see Evans, 2010). But Cummins adds to her theory the fact that living in hierarchical social relationships requires the development of a particular capacity for deontic reasoning in order to choose a strategic, or even prudent, course of action. She states:

Living within a dominance hierarchy requires an individual to engage in deontic reasoning continually. Lower ranking individuals must decide whether or not to engage in forbidden activities in order to secure a larger share of resources, and higher-ranking individuals must defend their privileged access to resources by detecting and punishing acts of cheating. Successfully negotiating the complex social norms implicit in non-human primate dominance hierarchies requires a particularly advanced capacity to detect and respond appropriately to permissions, prohibitions, threats, warnings, and obligations. (P. 470.)

For Cummins, the need to identify violations of deontic organizations is present in different species of non-human primates, and a capacity linked to reproductive success. This competence emerges early in human development, as the evidence in young children demonstrates (see Harris, 2012).

As will be seen in section 3, where a special role will be given to cooperation to explain the argumentative faculty, Cummins interestingly does not go into the problem of cooperativeness. She takes the results of experiments that test people's reactions to cheating, which is not the same as competing, to "show that reneging on a promise to cooperate is reacted to more strongly and more negatively than is competition alone (Rabbie, 1992; Weg \& Smith, 1993)" (p. 470). These results are wholly in line with the idea of seeing reasoning as a strategy based on reciprocal obligations and the detection of cheaters. On this matter, Cummins refers to Cosmides and Tooby's perspective as an incomplete theory because it does not explain why 
other species of primates apparently reason so effectively in deontic contexts. Cummins' solution is to trace

...the capacity for deontic reasoning to selective pressure favoring the evolution of reasoning strategies that determine survival within dominance hierarchies, and hence impact directly on reproductive success. This explanation is also consistent with the empirical observations that the capacity for deontic reasoning is apparent in the social interactions of species other than our own, and why it emerges early in human development. It combines the evolutionary emphasis of social exchange theory with the specific domains identified by pragmatic schema theory (i.e., permission, obligation, precaution, and warning). Most importantly, it generalizes and deepens the evolutionary account by positing a direct relationship between domain specific reasoning architecture and reproductive success. (P. 476.)

As will become apparent in my own account, human reproductive success is tied to basic reciprocal cooperation among members of a group in which honest, true and accurate representations are proposed to a receiver or listener.

\section{The reciprocal benefit of arguing}

Whether it is analyzed from the angle of evolutionary psychology, or from a broader cognitive frame, argumentation will be described as part of cooperative behaviour, because it is expressed through a linguistic mechanism or, in general, through a communicative symbolic system that presupposes a coordination of collective intentionality. It is necessary to highlight that argumentation always has been part of a cooperative effort to solve differences of opinion, since, if controversies would have been solved only through violent actions, they would have reduced the possibilities of survival or group growth. At the same time, to solve controversies only with the use of commands expressed by the leaders of a group (and with the implicit warrant of the use of force in case of disobedience), it would have reduced the probability of opting for more optimal solutions from less talented, less powerful or younger agents of the group.

Thus, cooperation, collective intentionality, and a stable communicative mechanism are the basic elements of this complex faculty. But, which evolutionary path did this competence follow to become a fully mental and collective ability? In order to answer this from an evolutionary angle, I will limit myself 
here to the evolutionary route of why argumentation works the way it does, and to explaining what type of adapted mental design is required for having this social behaviour. ${ }^{2}$ The explanation that follows uses some elements of an intense discussion reported in many different publications in the realm of evolutionary analysis of social communicative strategies.

I contend that argumentation works both as the competence through which beliefs and other contextual intentional states that are mutually beneficial (for all members of a group) are established, and as a competence that coordinates the decision-making on new courses of action. Both actions produce changes, and the only way to produce these changes is by means of a communicative behaviour that preserves the verbal or symbolic conflict as its core force, this is to say, a social mechanism that ensures the constant exchange of different states of affairs, achieved by continuously conflicting our representations. To argue that argumentation establishes beliefs and other mutually beneficial intentional states, closely follows a basic evolutionary antecedent, which ethology has identified in communication through signals, that is, a communicative action that co-evolved between sender and receiver in which both benefit from the interchange of such signals (Griebel \& Oller, 2008; MaynardSmith \& Harper, 2003). Each time there is a conflict and the agents involved feel the need to dissolve the disagreement to fulfill some or various simultaneous goals, then argumentation emerges. So, argumentation emerges, from the point of view of the group, every time that a coordination problem is at stake; and, from the point of view of the individual, every time that an agent wants to know the potential obstacles in terms of both branches: symbolic communication (content, representations), and opposite agents (people). ${ }^{3}$

Why is the faculty totally cooperative? Because, as Skyrms (2004) points out, misleading behaviour between the agents would harm all the participants in the group in the long run, which would make it impossible to achieve a beneficial and adequate equilibrium and a productive reciprocal group. ${ }^{4}$ The

\footnotetext{
${ }^{2}$ We should keep in mind that when evolutionary biologists work on the adaptation of an evolutionary strategy, they sometimes remember that adaptation traits do not always adapt perfectly to the environment. So the argumentation faculty should not be seen as an exception.

${ }^{3}$ This definition is somewhat similar to Godfrey-Smith \& Yegnashankaran's (2011) perspective regarding reasoning, in the sense that it is deliberative in function and dialogic in structure and origin.

${ }^{4}$ For a more detailed analysis of the evolution of moral virtue, considering a precise characterization of free riders, see Boehm (2012). For a good revision of the evolution of reciprocity and altruism, see Bowles \& Gintis (2011).

@ Cristián Santibáñez Yáñéz. Informal Logic, Vol.35, No. 2 (2015): pp. 167-182.
} 
idea of equilibrium here is used as a relational state in which the agents have some degree of cognitive parity, since they know that to give - good - reasons to find the adequate way to solve problems is an advantage. Once equilibrium was introduced, it can be said that argumentation became an evolutionary stable strategy.

In the same way as with language (Hurford, 2012), it is highly unlikely that argumentation could have flourished in a small group, given that the leaders would probably have used only their strength to maintain their power and status or to ritualize ways to solve problems according to their interests. As with language (Dunbar, 1993, 1998), the larger the group, the greater the need to persist in a stable strategy of distribution of beneficial beliefs (representations). In a group with a lot of members, ${ }^{5}$ an important dimension of the agent becomes essential: reputation. Those who are capable of administering the production, distribution and sanction (critical thinking) of reasons and claims, adapt better, because this act can be seen as generous and highly competitive and well-adapted behaviour. In fact, the delivering of good arguments could be a way to show altruism (Boehm, 2012; de Waal, 2009).

What kind of mental infrastructure is needed to properly participate in this social activity of giving reasons? I would like to suggest that argumentation requires the same capacity that intentions, or more generally mind-reading, presupposes, this is a recursive form: "I know that you know that I know..." In the particular case of arguing, the general mechanism can be labeled as an inferential recursive giving-reasons formula: "I know that you know that I know you evaluate my reasons..." So, knowing this amounts to a selective pressure to communicate good reasons. In argumentation, joint attention, shared hinge beliefs, collective acceptance and collective emotions are the core features of this complex faculty. In turn, as is well known, these features are part of the definition of collective intentionality. ${ }^{6}$

At this exact point, my account shares the basic assumption in all the standard theories of argumentation, which is that arguing is a social act and all social behaviour "has the collective intentionality of the participants" (Searle, 2007a, p. 9). As Tomasello (2014) has recently emphasized, collective intention-

\footnotetext{
${ }^{5}$ According to Richerson (2013; Richerson \& Boyd, 2005) the size of the group determines the cultural complexity in human beings, and cooperation among primates is limited to small groups.

${ }^{6}$ I resort to Searle's perspective $(1995,2005,2006,2007 \mathrm{a}, 2007 \mathrm{~b}, 2010)$ of collective intentionality while bearing in mind Tuomela's angle (1995, 2002, 2007, 2013).
}

(c) Cristián Santibáñez Yáñéz. Informal Logic, Vol.35, No. 2 (2015): pp. 167-182. 
ality is a phenomenon that goes hand in hand with cooperation (see also Tomasello et al, 2005; Tomasello et al, 2010). In order to be part of the collective intentionality we do not need a particular belief or specific intentional state; it is natural to our organization, since it is part of the structural background of human beings (Searle, 2010). Since shared intentionality appeared among human beings, at some point in the evolution process, ${ }^{7}$ collective action and the conversational mode became two of its essential characteristics.

The research and perspective summarized by Tomasello $(2008,2014)$ points in the same direction. The author assigns an infrastructural place to collective intentionality and to cooperation in the human community. A main concept of his approach (Tomasello, 2008, p. 105) is the notion of recursion, which I have used in the same vein. Recursion is the mental component that refers to the social fact characterized by an iterative underlying structure of explicit or implicit mutual knowledge when we send messages - "I know that you know that I know that..." From this, it can be inferred that human communication is recursive only because it is totally cooperative. For Tomasello communication is recursive since it is cooperative in the following terms: (1) there are norms of cooperation in human communication (for example, the simple turn-taking in dialogues), (2) there are objectives and shared intentions to reach certain goals or to produce certain results, (3) there is joint attention (for example, what is observed in infants to the effect of referential comprehension), and (4) there are communicative conventions in the common conceptual domain that we share with the others (cultural rules, for instance).

The notion of common knowledge sometimes is considered a broad term. At least three categories of common knowledge can be distinguished that are important for describing the argumentative faculty. First, there is an immediate perceptual environment common to all the participants and that in a communal context coexists with the experience from a shared background. Second, there is a common ground that emerges from two different processes: the process of goals, as in the case when the agents pursue a common objective and know that both are focused simultaneously on the elements that are relevant to their common objective; and the process of the results, as is the case when two agents that are together receive the same stimuli

\footnotetext{
${ }^{7}$ About the phylogenetic route of collective intentionality, see Tomasello (2008, pp. 172-241), Richerson \& Boyd (2005), Henrich \& Henrich (2007).
} 
and they realize that they did something in common. Third, there is a common ground of cultural generalizations.

This mental and social infrastructure can be seen as the design that underlies the function of arguing and gives sense to the evolutionary explanation offered above. It takes into account collective intentionality, cooperation, a stable communicative mechanism, and shared attention by pointing out that the role of the competence lies in producing beneficial arguments not only for the hearer but also for the speaker - and members of the surrounding group. The act of giving reasons must be understood in relation to the context in which reasons are uttered and the goals that are pursued in order to change representations, in order to critically value representations already established and to avoid unproductive social decisions.

\section{Conclusions}

In the following comments I will try to defend my proposal once more by highlighting the main points of the foregoing discussion.

First, arguing in order to produce a benefit for the group strengthens the reproductive capacity of the same group, its survival. In particular, convincing the members of the group to change a belief, representation or course of action, benefits the construction of a niche (Sterelny, 2003, 2008), the way for human beings to culturally modify the environment to their advantage. As Sterelny (2008: 215-216) highlights, adaptation means not only assimilation to the environment but also the assimilation of the environment to the needs of the agent.

Second, arguing through accurate representations is a mechanism by which a system of localization and robust tracking (Sterelny calls it robust tracking system) of sources of food and shelter can be obtained. The speaker who argues with true arguments (understood in a broad sense: valid, relevant and acceptable), will see an improvement of her reputation and, at the same time, will have more possibilities of receiving, due to the reciprocal behaviour that human beings develop through their actions, arguments that benefit her; and ultimately she will be labeled as a reliable source of correct/useful information and representations. Obviously, an agent can solve controversies with false arguments, fallacious moves, or even by manipulating the hearer, but the risks are really high, and sooner or later the group or other arguers will punish such unproductive behaviour. As is well summarized by Sperber \& Baumard (2012), mislead- 
ing behaviour severely harms the reputation and the possibilities of being benefited by future cooperation. ${ }^{8}$

At the same time, it must be remembered that argumentation is a mechanism of defense and anticipation, too. As Tomasello (2014, p. 24) states reporting the inferential processes of primates, our closest ancestors, we assimilate the central aspects of a problematic situation to a cognitive model that incarnates a general understanding of the intentionality involved. We use this model to make inferences about what has happened, could happen or could have happened, to explain it to the other, to warn the other or to anticipate the action of others or controversial events. This position of Tomasello is similar to Fletcher \& Carruthers' perspective (2012) in the sense that we have a metacognitive model whose role it is to monitor the production of actions, and from the point of view of argumentation to monitor reasons.

This last point deserves more attention. When agents share attentional scenarios and know that the recipient of a communication is evaluating their communicative behavior for purposes of understanding, for example (or for defensive purposes of the group), the communicator must be coupled with the set of beliefs, representations or perspectives that the hearer, or audience, has. So the cognitive skill based on a cultural background, is as follows: the agent includes in its perspective the angles of the other, which results in a constant effort of self-monitored and self-regulated behaviour, which in many cases and contexts works automatically and intuitively. ${ }^{9}$ This mental competence is by default dialogical. It's what Tomasello (2014, p. 79) calls "cooperativized cognition," allowing institutionalization (Searle, 1995) and conventionalization (Lewis 1969).

There are many other topics and issues to be solved. I think it is imperative that two of them be addressed. One is to

\footnotetext{
${ }^{8}$ Sperber and Baumard (2012), analyzing the function of moral behavior, point out that:

Cheating however may seriously compromise one's reputation and one's chances of being able to benefit from future cooperation. In the long run, co-operators who can be relied upon to act in a mutually beneficial manner are likely to do better in what may be called the 'cooperation market.' According to a standard evolutionary approach to morality that we may call the 'mutualistic approach', the biological function of moral behaviour is precisely to help individuals gain a good reputation as cooperators (Alexander, 1987; Krebs, 1998; Trivers, 1971). (2012, p. 495.)

${ }^{9}$ I am thinking of the literature on the dual system approach to mind (Evans, 2010; Kahneman, 2011).

(c) Cristián Santibáñez Yáñéz. Informal Logic, Vol.35, No. 2 (2015): pp. 167-182.
} 
understand argumentation as a Nash equilibrium, an equilibrium that is maintained between the participants since each one knows that the other knows that the speaker as well as the hearer (both taking their positions during the argumentative dialogue) will cooperate by offering reasons because this is expected; ${ }^{10}$ and a second issue is to explain the capacity of the argumentative decoupling of premises and conclusions, that is, the functional flexibility of using information in a loop (data becomes a backing, a claim becomes a warrant), something that is potentially present in Toulmin's model.

Acknowledgements: I am grateful to two anonymous reviewers for their detailed criticism of the original version of this paper. Without the financial support of the Chilean National Commission of Science, Project number 1130584, the research contained in this paper would have been impossible to accomplish.

\section{References}

Boehm, Ch. (2012). Moral Origins. The Evolution of Virtue, Altruism, and Shame. New York: Basic Books.

Bowles, S., \& Gintis, H. (2011). A Cooperative Species. Human Reciprocity and its Evolution. Princeton: Princeton University Press.

Bratman, M. (2014). Shared Agency. A planning Theory of Acting Together. New York: Oxford University Press.

Cosmides, L. (1989). The logic of social exchange: Has natural selection shaped how human reason? Studies with the Wason selection task. Cognition, 31: 187-276.

Christensen, W. (2010). The decoupled representation theory of the evolution of cognition - a critical assessment. The British Journal for the Philosophy of Science, 61(2): 361-405.

Cummins, D. (1996a). Evidence for the innateness of deontic reasoning. Mind \& Language, 11: 160-190.

Cummins, D. (1996b). Evidence of deontic reasoning in 3- and 4- year-olds. Memory \& Cognition, 24: 823-829.

Cummins, D. (1996c). Dominance Hierarchies and the Evolution of Human Reasoning. Minds and Machines, 6: 463-480.

Cummins, D. (1998). Social norms and other minds: The evolutionary roots of higher cognition. In D. Cummins, \& C. Al-

\footnotetext{
${ }^{10}$ This way of understanding the Nash equilibrium is applied to the notion of shared agency in Bratman (2014, p. 5).

(C) Cristián Santibáñez Yáñéz. Informal Logic, Vol.35, No. 2 (2015): pp. 167-182.
} 
len, (Eds.), The evolution of mind (pp. 30-50). New York: Oxford University Press.

Cummins, D. (2003). The Evolution of Reasoning. In J. Leighton, \& R. Sternberg, (Eds.), The nature of reasoning (pp. 339-374). Cambridge: Cambridge University Press.

De Waal, F. (2009). The Age of Empathy. Nature's Lessons for a Kinder Society. London: Souvenir Press.

Dunbar, R. (1993). Coevolution of neocortical size, group size and language in humans. Behavioral and Brain Sciences, 16 (4): $681-735$.

Dunbar, R. (1998). Grooming, Gossip, and the Evolution of Language. Cambridge, MA: Harvard University Press

van Eemeren, F.H., \& Grootendorst, R. (1992). Argumentation, Communication and Fallacies. A Pragma-dialectical Perspective. Hillsdale, NJ: Lawrence Erlbaum Associates.

van Eemeren, F.H. van, \& Grootendorst, R. (2004). A Systematic Theory of Argumentation. The pragma-dialectical approach. Cambridge: Cambridge University Press.

Evans, J. (2010). Thinking Twice. Two Minds in One Brain. New York: Oxford University Press.

Fletcher, L., \& Carruthers, P. (2012). Metacognition and Reasoning. Philosophical Transactions. The Royal Society of Biology, 367: 1366-1378.

Godfrey-Smith, P., \& Yegnashankaran, K. (2011). Reasoning as deliberative in function but dialogic in structure and origin. Behavioral and Brain Sciences, 34 (2): 80.

Griebel, U., \& Oller, D. (2008). Evolutionary Force Favoring Communicative Flexibility. In D. Oller, \& U. Griebel, (Eds.), Evolution of Communicative Flexibility (pp. 9-40). Cambridge, MA: The MIT Press.

Hample, D. (2005). Arguing: Exchanging Reasons Face to Face. Mahwah, NJ: Erlbaum.

Harris, P. (2012). Trusting What You're Told. How Children Learn from Others. Cambridge, MA: Harvard University Press.

Henrich, N., \& Henrich, J. (2007). Why Humans Cooperate. A Cultural and Evolutionary Explanation. New York: Oxford University Press.

Hurford, J. (2012). The Origins of Grammar. New York: Oxford University Press.

Kahneman, D. (2011). Thinking, Fast and Slow. London: Allen Lane.

Laland, K., \& Brown, G. (2002). Sense \& Nonsense. Evolutionary Perspectives on Human Behaviour. New York: Oxford University Press. 
Lewis, D. (1969). Convention. Cambridge, MA: Harvard University Press.

Maynard-Smith, J., \& Harper, D. (2003). Animal Signals. New York: Oxford University Press.

Mercier, H., \& Sperber, D. (2011). Why do human reason? Arguments for an argumentative theory. Behavioral and Brain Sciences, 34 (2): 57-74.

Richerson, P. (2013). Human evolution: Group size determines cultural complexity. Nature, 503, 351-352.

Richerson, P., \& Boyd, R. (1999). Complex societies- The Evolutionary origins of a crude superorganism. Human Nature, 10: 253-289.

Richerson, P., \& Boyd, R. (2005). Not by Genes Alone. How Culture Transformed Human Evolution. Chicago: Chicago University Press.

Searle, J. (1995). The Construction of Social Reality. New York: The Free Press.

Searle, J. (2005). What is an Institution?. Journal of Institutional Economics, 1 (1): 1-22.

Searle, J. (2006). Social Ontology: Some basic principles. Anthropological Theory, 6 (1): 12-29.

Searle, J. (2007a). Social Ontology and the Philosophy of Society. In E. Margolis, \& S. Laurence, (Eds.), Creations of the Mind. Theories of Artefacts and their Representation (pp. 317). New York: Oxford University Press.

Searle, J. (2007b). What is language: some preliminary remarks. In S. Tsohatzidis (Ed.), John Searle's Philosophy of Language. Force, Meaning and Mind (pp. 15-48). New York: Cambridge University Press.

Searle, J. (2010). Making the Social World. The Structure of Human Civilization. New York: Oxford University Press.

Skyrms, B. (2004). The Stag Hunt and the Evolution of Social Structure. New York: Cambridge University Press.

Sperber, D. (2001). An evolutionary perspective on testimony and argumentation. Philosophical Topics, 29: 401-413.

Sperber, D., \& Baumard, N. (2012). Moral Reputation: An Evolutionary and Cognitive Perspective. Mind \& Language, 27 (5), 485-518

Sterelny, K. (2003). Thought in a Hostile World. The Evolution of Human Cognition. Oxford: Blackwell Publishing.

Sterelny, K. (2008). Language and Niche Construction. In K. Oller. \& U. Griebel. (Eds.), Evolution of Communicative Flexibility (pp. 215-232). Cambridge, MA: MIT Press.

Tindale, C. (1999). Acts of Arguing. A Rhetorical Model of Argument. Albany, NY: SUNY Press. 
Tomasello, M. (2008). Origins of Human Communication. Cambridge, MA: The MIT Press.

Tomasello, M. (2014). A Natural History of Human Thinking. Cambridge, MA: Harvard University Press.

Tomasello, M., et al. (2005). Understanding and sharing intentions: the origins of cultural cognition. Behavioral and Brain Sciences, 28: 675-735.

Tomasello, M. et al. (2010). Why We Cooperate. Cambridge, MA: The MIT Press.

Toulmin, S., Rieke, R., \& Janik, A. (1979). An Introduction to Reasoning. New York: Macmillan.

Tuomela, R. (1995). The Importance of Us. A Philosophical Study of Basic Social Notions. Stanford: Stanford University Press.

Tuomela, R. (2002). The Philosophy of Social Practices. A Collective Acceptance View. New York: Cambridge University Press.

Tuomela, R. (2007). The Philosophy of Sociality. The Shared point of View. New York: Oxford University Press.

Tuomela, R. (2013). Social Ontology: Collective Intentionality and Group Agents. New York: Oxford University Press.

Walton, D. (2013). Methods of Argumentation. New York: Cambridge University Press. 